\title{
Modification of Cation-Exchange Membranes with Polyelectrolyte Multilayers to Tune Ion Selectivity in Capacitive Deionization
}

\author{
Sevil Sahin, Jouke E. Dykstra, Han Zuilhof, Rafael L. Zornitta,* and Louis C.P.M. de Smet*
}

Cite This: ACS Appl. Mater. Interfaces 2020, 12, 34746-34754

Read Online

ABSTRACT: Capacitive deionization (CDI) is a desalination technique that can be applied for the separation of target ions from water streams. For instance, mono- and divalent cation selectivities were studied by other research groups in the context of water softening. Another focus is on removing $\mathrm{Na}^{+}$ from recirculated irrigation water (IW) in greenhouses, aiming to maintain nutrients. This is important as an excess of $\mathrm{Na}^{+}$has toxic effects on plant growth by decreasing the uptake of other nutrients. In this study, we investigated the selective separation of sodium $\left(\mathrm{Na}^{+}\right)$and magnesium $\left(\mathrm{Mg}^{2+}\right)$ in MCDI using a polyelectrolyte multilayer (PEM) on a standard grade cation-exchange membrane (Neosepta, CMX). Alternating layers of poly(allylamine hydro-
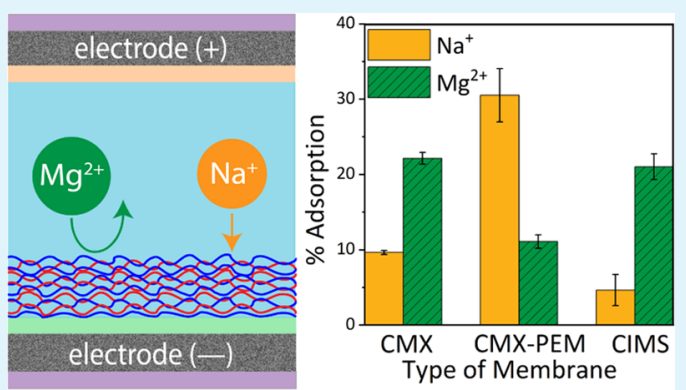
chloride) (PAH) and poly(styrene sulfonate) (PSS) were coated on a CMX membrane (CMX-PEM) using the layer-by-layer (LbL) technique. The layer formation was examined with X-ray photoelectron spectroscopy (XPS) and static water contact angle measurements (SWA) for each layer. For each membrane, i.e., the CMX-PEM membrane, CMX membrane, and for a special-grade cation-exchange membrane (Neosepta, CIMS), the $\mathrm{Na}^{+} / \mathrm{Mg}^{2+}$ selectivity was investigated by performing MCDI experiments, and selectivity values of $2.8 \pm 0.2,0.5 \pm 0.04$, and $0.4 \pm 0.1$ were found, respectively, over up to 40 cycles. These selectivity values indicate flexible switching from a $\mathrm{Mg}^{2+}$-selective membrane to a $\mathrm{Na}^{+}$-selective membrane by straightforward modification with a PEM. We anticipate that our modular functionalization method may facilitate the further development of ion-selective membranes and electrodes.

KEYWORDS: mono/divalent cation selectivity, polyelectrolyte multilayers, capacitive deionization, cation-exchange membrane, sodium removal

\section{INTRODUCTION}

Over the last decade, capacitive deionization (CDI) has been used for ion-selective desalination, ${ }^{1-3}$ especially for the recovery of nutrients (phosphate ${ }^{4-6}$ and nitrate ${ }^{7-10}$ ) and valuable ions (lithium, ${ }^{11}$ potassium, ${ }^{12}$ ammonia, ${ }^{13}$ fluoride $^{14}$ ), removal of heavy metals, ${ }^{15-18}$ and water softening. ${ }^{19-21}$ The selective capture of target ions from a multi-ionic solution or the enrichment of the target ion by removing the competing ions is the main idea behind these applications. ${ }^{1}$ For instance, the separation of monovalent from divalent cations using CDI has been vastly studied in the context of water softening. ${ }^{19-21}$ Efforts were made on selective materials or optimizations of experimental parameters to selectively remove hardness ions $\left(\mathrm{Mg}^{2+}\right.$ and $\left.\mathrm{Ca}^{2+}\right)$ from alkali metal cations. Another focus is on removing $\mathrm{Na}^{+}$from recirculated irrigation water (IW) in greenhouses, aiming to maintain nutrients. ${ }^{22-25}$ This is important as an excess of $\mathrm{Na}^{+}$has toxic effects on plant growth by decreasing the uptake of other nutrients. ${ }^{26}$

CDI is a desalination technique in which ions are removed from brackish water by an electric potential applied to a pair of electrodes. ${ }^{27,28}$ As a result, the outlet water contains a lower salt concentration. The combination of ion-exchange membranes (IEMs) and CDI is called membrane capacitive deionization (MCDI), which improves charge efficiency of the electrodes and provides higher separation capacity compared to CDI. ${ }^{27}$ While there is an ongoing debate on the energy efficiency and operational costs of MCDI compared to other well-established desalination technologies, ${ }^{29-32}$ it has also been shown that MCDI can be competitive, at least for salt concentrations up to $40 \mathrm{mM} .^{33}$ IEMs have fixed charges that allow the transport of counterions (anions in an anionexchange membrane, cations in a cation-exchange membrane) and prevent the unwanted transport of co-ions, resulting in an increased charge efficiency. ${ }^{28,34-36}$

Numerous studies have been published on separation of monovalent cations from divalent cations using multi-ionic solutions in CDI. ${ }^{20,21,37-41}$ For instance, Seo et al. showed higher removal rates for di- over monovalent cations by optimizing the pore structure and wettability of carbon

Received: March 26, 2020

Accepted: June 26, 2020

Published: June 26, 2020 
electrodes, ${ }^{38}$ the most used type of CDI electrodes. Zhao et al. achieved time-dependent selectivity using a solution with a concentration ratio of $\mathrm{Na}^{+} / \mathrm{Ca}^{2+}=5$, where in the early stage of the desalination process, the dominantly present $\mathrm{Na}^{+}$ions were preferentially electrosorbed, while later on they were gradually replaced by the minority $\mathrm{Ca}^{2+}$ cations. ${ }^{39}$ Another study from Hou and Huang also demonstrated a higher affinity toward divalent cations using carbon electrodes. ${ }^{41}$ Recently, $\mathrm{He}$ et $\mathrm{al}^{20}$ and Wang and $\mathrm{Lin}^{21}$ studied the dependence of selectivity on operating conditions such as current density and hydraulic retention time in MCDI operated in a constant current mode. They implemented standard-grade IEMs in a CDI cell and reported higher $\mathrm{Ca}^{2+}$ over $\mathrm{Na}^{+}$selectivity. Besides the optimization of operational conditions, introducing a selective layer can also tune the selectivity. Yoon et al. ${ }^{40}$ and Kim et al. ${ }^{37}$ prepared composite coatings onto carbon electrodes to obtain $\mathrm{Ca}^{2+}$ over $\mathrm{Na}^{+}$selectivities in MCDI.

One interesting and alternative way of introducing selectivity to CDI-based separations is using layer-by-layer ( $\mathrm{LbL}$ )-coated polyelectrolyte multilayers (PEMs). PEMs, which were first demonstrated by Decher in the early $1990 \mathrm{~s},{ }^{42,43}$ are composed of alternating layers of oppositely charged polymers. They are attractive because of their high stability and easy and cheap preparation, ${ }^{44}$ which provides versatile control over the physicochemical properties of surfaces. Surface characteristics such as chemical charge, morphology, and swelling properties can be tuned by sequentially constructed PEMs. Therefore, PEMs can regulate the interactions with surrounding environments. ${ }^{4-49}$ PEMs have been employed in ion separation, mainly pressure-driven, ${ }^{50,51}$ and more recently also electrodriven. ${ }^{52-54}$ These studies showed that monovalent ion permeation and divalent ion rejection can be controlled by tuning the PEM properties. The mechanism of selectivity is based on the Donnan charge exclusion effect. ${ }^{54,55}$ When the outermost charge of the surface has the same charge as the divalent ion, divalent ions are rejected more compared to monovalent ions due to their higher charge density. ${ }^{56}$

Based on these advancements, we now study, for the first time, the combination of PEMs and CDI. So far, several research groups have investigated the use of PEMs for the selective ion separation using different combinations of monoand divalent cations (i.e., $\mathrm{Na}^{+} / \mathrm{Ca}^{2+}, 52 \mathrm{~K}^{+} / \mathrm{Mg}^{2+},{ }^{48} \mathrm{Li}^{+} / \mathrm{Co}^{2+}$, $\mathrm{Na}^{+} / \mathrm{Mg}^{2+54}$ ) and they all reported a monovalent cation selectivity. Out of these combinations, we chose to study $\mathrm{Na}^{+}$/ $\mathrm{Mg}^{2+}$ selectivity of PEM where the molar ion ratio is $1: 1$.

In this study, we aimed to develop a simple method to separate $\mathrm{Na}^{+}$from $\mathrm{Mg}^{2+}$ in a binary solution by switching the selectivity of a commercial cation-exchange membrane. The feasibility of a PEM on a standard grade cation-exchange membrane (Neosepta, CMX) was investigated in MCDI operation for the selective separation of $\mathrm{Na}^{+}$and $\mathrm{Mg}^{2+}$. Alternating layers of poly(allylamine hydrochloride) (PAH) and poly(styrene sulfonate) (PSS) were prepared onto a CMX membrane (CMX-PEM) using the LbL technique. The layer formation was examined with X-ray photoelectron spectroscopy (XPS) and static water contact angle measurements (SWA) for each layer. Then, the CMX-PEM membrane was implemented in an MCDI cell, which was operated in a constant voltage operation mode. During the operation, samples were collected from the effluent solution. The collected samples were analyzed with inductively coupled plasma optical emission spectrometry (ICP-OES) afterward. The selectivity value was calculated based on the adsorption ratio of $\mathrm{Na}^{+}$over $\mathrm{Mg}^{2+}$. The selectivity, reproducibility, and performance of the operation were compared with an unmodified CMX membrane and a special-grade cationexchange membrane (Neosepta, CIMS) under the same conditions. The CIMS membrane was chosen as an additional reference membrane due its cross-linked outermost layer, which showed a higher monovalent cation selectivity in electrodialysis. ${ }^{54}$ Finally, the stability and selectivity of the PEM-CMX membrane were tested in an MCDI operation for 40 cycles, and an outlook on the potential of this novel approach was provided.

\section{MATERIALS AND METHODS}

Materials. Poly(allylamine hydrochloride) (PAH, $M_{\mathrm{w}}=17500$ $\mathrm{Da})$, poly(sodium 4-styrenesulfonate) (PSS, $\left.M_{w}=70000 \mathrm{Da}\right)$, sodium chloride $(\mathrm{NaCl}, \geq 99 \%)$, anhydrous magnesium chloride $\left(\mathrm{MgCl}_{2}, \geq 98 \%\right)$, and sodium 2-mercaptoethanesulfonate (MESNA, analytical standard, $\geq 98.0$ ) were purchased from Sigma-Aldrich. Hydrochloric acid (36.5-28.0\% NF grade) was purchased from VWR International. Nitric acid (65\%, for analysis) and ethanol (absolute) were purchased from Merck Millipore. Acetone (HPLC grade, 99.9\%) and dichloromethane (stabilized with amylene) were purchased from BIOSELVE BV. All chemicals were used as received without further purification. The inorganic salts were kept in a vacuum oven overnight prior to use.

Neosepta cation-exchange (CMX), anion-exchange (AMX), and monovalent cation-selective (CIMS) membranes (Astom Corp., Japan) were soaked in a solution of $4 \mathrm{mM} \mathrm{NaCl}$ and $4 \mathrm{mM} \mathrm{MgCl}$ for at least $48 \mathrm{~h}$ before use. The porous carbon electrodes, which were deposited on a graphite foil substrate, were supplied by Voltea BV, Netherlands. Glass fiber prefilters $(25 \mathrm{~mm}$ in diameter) with a pore size of $2.0 \mu \mathrm{m}$ (Merck Millipore) were used as a spacer for MCDI experiments. Flat substrates of gold sputtered on glass $(1 \times 1 \mathrm{~cm})$ were purchased from ECsens. Milli-Q water $(18.2 \mathrm{M} \Omega \cdot \mathrm{cm}$, Milli-Q Integral 3 system, Millipore) was used to prepare salt and polyelectrolyte solutions.

Layer-By-Layer (LbL) Coating onto Membrane. The use of PEMs in pressure- and electro-driven ion-selective separations have been reported in previous studies. ${ }^{49,51,54,57-59}$ Out of the several PEM systems and preparation conditions that have been used, we adopted a procedure of Bruening and co-workers ${ }^{58}$ and built (PAH/PSS) ${ }_{5} \mathrm{PAH}$ layers. The pretreated CMX membrane was modified by alternating dipping in PAH (polycation) (0.02 $\mathrm{M} \mathrm{PAH}$ in $1 \mathrm{M} \mathrm{NaCl}, \mathrm{pH}=2.3$ ) and PSS (polyanion) (0.02 M PSS in $0.5 \mathrm{M} \mathrm{NaCl}, \mathrm{pH}=2.3$ ) solutions for $10 \mathrm{~min}$ each to form the multilayers. After each layer coating, the CMX was soaked in Milli-Q water $(3 \times 3 \mathrm{~min})$ to remove any weakly attached polyelectrolytes. The CMX membrane was coated with 11 polyelectrolyte layers in total, and the membrane was referred to as CMX-PEM. The CMX-PEM was stored in a solution of $4 \mathrm{mM} \mathrm{NaCl}$ and $4 \mathrm{mM} \mathrm{MgCl}$.

Layer-By-Layer (LbL) Coating on Gold Substrates. The growth and properties of the multilayers were characterized by gold model substrates. Although gold is chemically different from IEMs, the bulk and surface properties of PEMs are not dependent on the type of surface characteristics of the substrate after a sufficient number of layers, ${ }^{50,54}$ making gold a suitable model surface. Prior to LbL coating, gold substrates were sonicated for $5 \mathrm{~min}$ in Milli-Q water and dried in a stream of argon. Sonication was repeated with acetone, ethanol, and dichloromethane, and the gold substrates were subsequently cleaned from organic material by $5 \mathrm{~min}$ of air-based plasma by a plasma cleaner (Diener electronic GmbH, Germany). ${ }^{60}$ Afterward, the surfaces were immersed in a $10 \mathrm{mM}$ MESNA solution overnight. Thiol groups of MESNA form strong dative bonds (40-50 $\mathrm{kcal} / \mathrm{mol}$ ) with gold surfaces, while the sulfonate groups $\left(\mathrm{R}_{-} \mathrm{SO}_{3}{ }^{-}\right)$of MESNA supply a negative surface charge.$^{61}$ Then, the gold substrates were coated with the PEM using the same LbL procedure as the one employed for the CMX before drying the substrates in a vacuum oven at $30{ }^{\circ} \mathrm{C}$. 
Characterizations. The properties of the multilayers were first characterized using X-ray photoelectron spectroscopy (XPS), static water contact angle measurements (SWA), spectroscopic ellipsometry, and atomic force microscopy (AFM).

SWA values were measured using a Krüss drop shape analyzer (DSA 30) by depositing Milli-Q water drops of $3 \mu \mathrm{L}$ onto the PEMcoated gold surface. Contact angles were measured with a chargecoupled device (CCD) camera using a sessile drop method. For each surface, the contact angle value was the average value of three measurements on different locations of the samples to study the homogeneity of the coating.

The XPS spectra of PEM-coated gold substrates were obtained (20 scans each experiment) by a JPS-9200 photoelectron spectrometer (JEOL, Japan) under ultrahigh vacuum conditions. The spectra were obtained using a monochromatic $\mathrm{Al} \mathrm{K} \alpha$ source at $12 \mathrm{kV}$ and $20 \mathrm{~mA}$. All spectra were corrected with Shirley background fitting and processed with CASA XPS software (version 2.3.16). The PEMcoated gold substrates were analyzed by spectroscopic ellipsometry. The dry (optical) thickness of the PEM coating was measured using an Accurion Nanofilm_ep4 imaging ellipsometer. The ellipsometric data were acquired in air at room temperature using light in a wavelength range of $\lambda=400.6-761.3 \mathrm{~nm}$ at an angle of incidence of $50^{\circ}$. The data were fitted with EP4 software using a multilayer model (used refractive index of gold: 1.397).

The AFM images of air-dried samples of CMX and PEM-CMX were acquired by an Asylum Research MFP-3D SA AFM (Oxford Instruments, United Kingdom) in amplitude and height modes with a scanning size of $5 \mu \mathrm{m} \times 5 \mu \mathrm{m}$.

Electrosorption Experiments. The experiments were performed using a lab-scale MCDI cell with dimensions of $6 \mathrm{~cm} \times 10.5 \mathrm{~cm} \times$ $18.5 \mathrm{~cm}$ (total volume of $70 \mathrm{~mL}$ ). The cell with two carbon electrodes $(5.6 \mathrm{~cm} \times 6.0 \mathrm{~cm})$, each with a square opening inside $(1.5 \mathrm{~cm} \times 1.5$ $\mathrm{cm})$, a CMX, an AMX, and a spacer was firmly assembled. The water enters the MCDI cell and flows radially to the outlet in the bottom center (schematic representation of the MCDI system can be found in the Supporting Information, SI), Figure S1. At the exit of the cell, a conductivity probe and a $\mathrm{pH}$ electrode record the conductivity and $\mathrm{pH}$ online. A port in between conductivity and $\mathrm{pH}$ probes was used for sampling during the experiments. The deaerated feed solution $(5 \mathrm{~L}$ of $4 \mathrm{mM} \mathrm{NaCl}$ and $4 \mathrm{mM} \mathrm{MgCl} 2$ ) was pumped through the system at a constant flow rate $(7.5 \mathrm{~mL} / \mathrm{min})$ using a peristaltic pump (Masterflex). We note that given the large volume of the feed solution, the operation mode behaves like a single-pass mode. ${ }^{62} \mathrm{~A}$ potentiostat (Autolab PGSTAT302N, Metrohm) provided a charging voltage of $1.0 \mathrm{~V}$ and a discharge voltage of $0 \mathrm{~V}$ (short circuit) during the electrosorption and regeneration, respectively. The conductivity (conductivity module 856, Metrohm) and $\mathrm{pH}$ (flat membrane, combined $\mathrm{pH}$ electrode, Metrohm) were monitored online. The electrosorption/desorption experiments were carried out for 10 cycles of $40 \mathrm{~min}$ each, except for the stability test of the CMX-PEM membrane, which included 40 cycles.

Depending on the experiment, a CMX, CMX-PEM, or CIMS membrane was used as a cation-exchange membrane (Figure 1). All CDI experiments were performed at least three times for each membrane. During three cycles, i.e., adsorption and desorption of each experiment, eight samples (for each adsorption or desorption steps) were collected for further analysis. The samples (each $1.5 \mathrm{~mL}$ ) were taken at $20,120,220,320,420,600,900$, and $1100 \mathrm{~s}$ of each adsorption step. After switching the sample port, a sample was taken after $15 \mathrm{~s}$ to account for the dead volume between the cell and the point of sampling.

Inductively coupled plasma atomic emission spectroscopy (PerkinElmer Avio 500 ICP-OES) was used to measure the $\mathrm{Na}^{+}$ and $\mathrm{Mg}^{2+}$ concentrations of the samples. The argon flow to produce the plasma was set to $10 \mathrm{~L} / \mathrm{min}$. The high-energy-based Avio 500 ICP-OES polychromator with two sulfur chemiluminescence detectors (SCD) covered a spectral range of $163-782 \mathrm{~nm}$, with a measuring resolution of $0.006 \mathrm{~nm}$ at $200 \mathrm{~nm}$. The samples were diluted 20 times with a $1 \%$ nitric acid solution before measurement. The selectivity of $\mathrm{Na}^{+}$over $\mathrm{Mg}^{2+}(\rho$, sometimes also defined as $\beta$ in

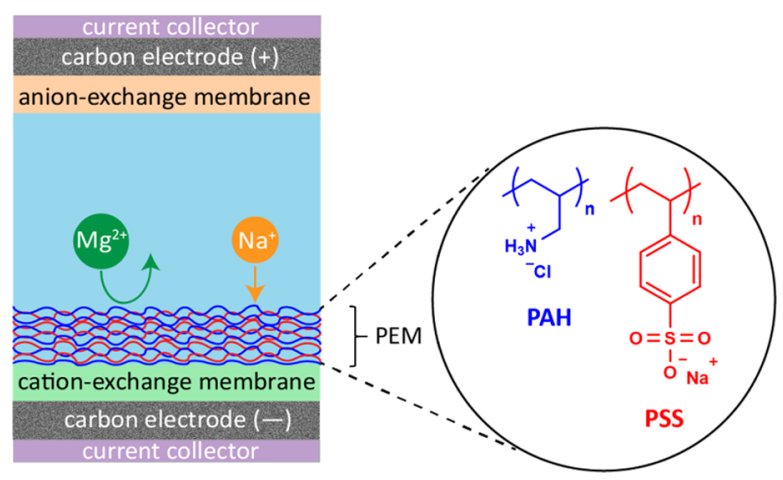

Figure 1. Schematic representation of the cell configuration. CMXPEM represents the membrane that was modified with polyelectrolytes (PAH and PSS). For each type of experiment, either CMX, CMX-PEM, or CIMS membranes were used as a cation-exchange membrane.

the literature ${ }^{63}$ ) was calculated according to eq $1,{ }^{20,21}$ where $c_{0}$ and $c_{\mathrm{f}}$ represent the initial and final ion concentrations in the solution, respectively

$$
\rho_{\mathrm{Mg}}^{\mathrm{Na}}=\frac{\left(c_{0, \mathrm{Na}^{+}}-c_{\mathrm{f}, \mathrm{Na}}{ }^{+}\right)}{c_{0, \mathrm{Na}^{+}}} / \frac{\left(c_{0, \mathrm{Mg}^{2+}}-c_{\mathrm{f}, \mathrm{Mg}}{ }^{2+}\right)}{c_{0, \mathrm{Mg}^{2+}}}
$$

The charge efficiency $(\Lambda)$ and the specific energy consumption $(\eta$, $\mathrm{kJ} / \mathrm{mg}$ ) for the charging step were calculated using eqs 2 and 3 , respectively, in which, $F$ is the Faraday constant $(96485.3 \mathrm{C} / \mathrm{mol}), z$ is the ion valence $\left(+2\right.$ for $\mathrm{Mg}^{2+}$, and +1 for $\left.\mathrm{Na}^{+}\right), \Delta n$ is the total amount of salt adsorbed (mol), $I$ is the current measured during the electrosorption step, which runs from $t_{1}$ (start of adsorption) to $t_{2}$ (end of adsorption), $V_{\text {cell }}$ is the cell voltage applied during the experiment, $m_{\mathrm{sr}}$ is the total mass of salt removed $(\mathrm{g})$ during the desalination process, and $M_{\mathrm{w}}$ is the molecular weight of the salt. The salt adsorption capacity (SAC) is calculated by dividing the amount of adsorbed salt (in $\mathrm{mg}$ ) by the mass of the carbon electrode $\left(m_{\text {electrode }}=\right.$ $1.79 \mathrm{~g})$.

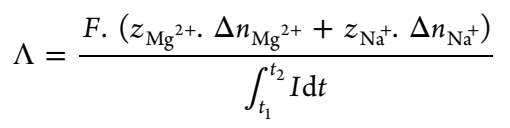

$$
\begin{aligned}
& \eta=V_{\text {cell }} \cdot \frac{\int_{t_{1}}^{t_{2}} I \mathrm{~d} t}{m_{\mathrm{sr}}} \\
& \mathrm{SAC}=\frac{\left(M_{\mathrm{wMgCl}_{2}} \cdot \Delta n_{\mathrm{Mg}^{2+}}+M_{\mathrm{wNaCl}} \cdot \Delta n_{\mathrm{Na}^{+}}\right)}{m_{\text {electrode }}}
\end{aligned}
$$

\section{RESULTS AND DISCUSSION}

Characterization of Multilayers. To study whether the layer build-up was successful, gold substrates were characterized after each layer addition via SWA and XPS analyses (Figure 2).

The wettability of the gold substrates coated with a PEM was studied with SWA measurements (Figure 2A). The first data point belongs to the pretreated gold substrate (MESNA$\mathrm{Au}$ ). Upon the addition of PE layers, the SWA data shows an odd-even effect. When the PSS was the top layer, the contact angle was lower than the layer with $\mathrm{PAH}$ on top, indicating that the PSS-terminated multilayers were more hydrophilic than the PAH-terminated ones. This is in agreement with similar studies reported in the literature regarding the hydrophilicity of the layers and their odd-even effect ${ }^{64-66}$ and it shows the successful build-up of 11 layers. 


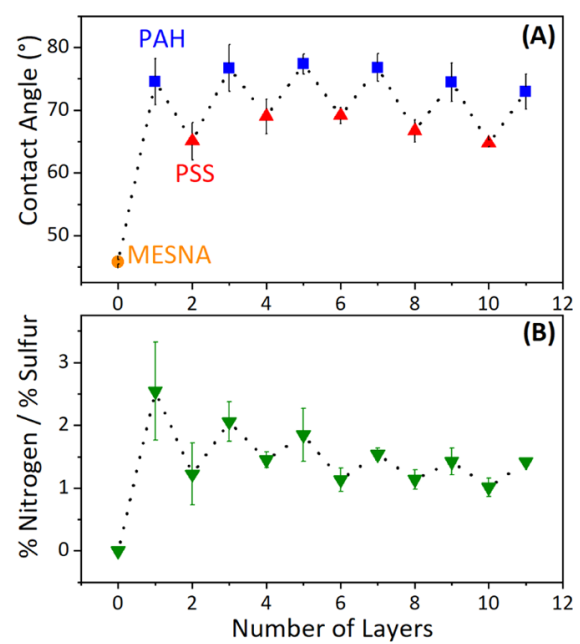

Figure 2. Surface characterization of gold substrates. Odd number layers have PAH and even number layers have PSS as the outermost layer. The initial data point is the MESNA-coated gold substrate. (A) Static water contact angle data show wettability of the outermost layer with increased number of layers. (B) Nitrogen/sulfur atomic ratios were obtained from wide-scan X-ray photoelectron spectra for each number of layers. (Reported data is based on three samples per data point and three measurements for each sample. Dotted lines are guide to eye).

The chemical composition of the surface of the substrates was measured with XPS after the addition of each layer (Figure 2B). The \% abundances of nitrogen (N) (only present in $\mathrm{PAH}$ ) and sulfur (S) (only present in PSS) were obtained from XPS wide-scan spectra. This was followed by the calculation of the N/S ratio data that, just like the SWA studies, showed an alternating trend, indicating the successful deposition of $\mathrm{PAH}$ and PSS layers. ${ }^{65,67}$ Wide-scan XPS spectra of the layers (Figure S2) and elemental composition as a function of the number of layers (Figure S3) can be found in the Supporting Information. Next to the SWA and XPS data, also AFM and ellipsometry confirm the presence of the PEMs (Figure S4 and related text).

MCDI Performance. The performance of the CMX-PEM membrane was evaluated based on conductivity and current data obtained for a 40-cycle constant voltage experiment. Figure 3 shows the data obtained for the adsorption steps 4-6, 24-26, and 37-39 with a salt mixture of $4 \mathrm{mM} \mathrm{NaCl}$ and 4 $\mathrm{mM} \mathrm{MgCl}$. The current reached its maximum and minimum values during adsorption and desorption, respectively (Figure 3A). The Coulombic efficiency and the amount of charge were found to be stable throughout the adsorption steps (Supporting Information, Table S1). Figure 3B indicates the change in the effluent conductivity as a function of time at given adsorption steps. The decrease and increase in conductivity indicate electrosorption and desorption of ions, respectively. At the end of each step, the effluent conductivity returned to the feed conductivity value demonstrating the saturation of electrodes (all cycles are provided in the Supporting Information, Figure S5).

Comparison of Ion Selectivities. Figure 4 shows the effluent concentration of $\mathrm{Na}^{+}$and $\mathrm{Mg}^{2+}$ as a function of time, both for the adsorption and desorption step of an electrosorption cycle in a constant voltage operation. The ions are adsorbed faster in the early stage of each electrosorption step. Therefore, the adsorption rate of ions reached a maximum

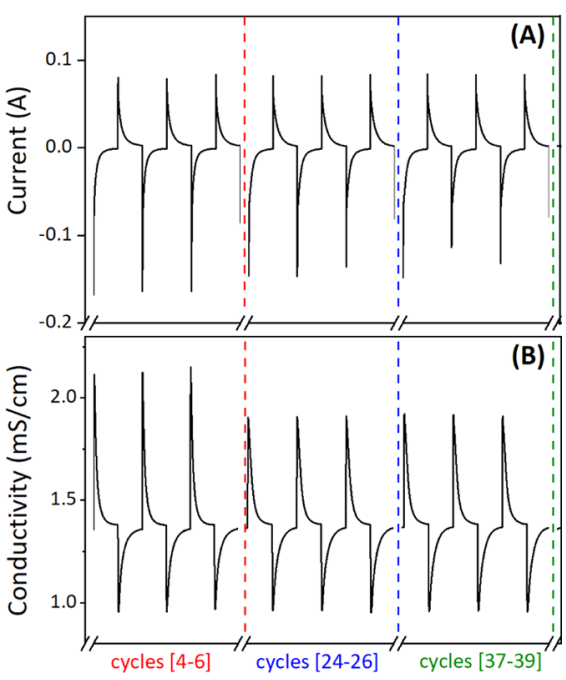

Figure 3. MCDI operation of the CMX-PEM membrane for cycles $4-6,24-26$, and 37-39. Time-course variation of the (A) current and (B) effluent conductivity data at a constant voltage process (dashed lines are guide to eye).

value, here, around $\sim 120 \mathrm{~s}$. After this point, the adsorption rate started to decrease and eventually ion concentrations returned to their initial values, suggesting that electrodes became saturated at the end of each adsorption step. In a constant voltage operation, the current changes during the adsorption steps. As a result, the relative adsorption rate of each type of cation changes as well, indicating that the selectivity can be time-dependent, which refers to the variation in ion selectivity during electrosorption, as already described in the literature. $^{18,39,68,69}$ The time where the maximum selectivity value was observed $(\sim 220 \mathrm{~s})$ was abbreviated as $t_{\mathrm{s}}$. At $t_{\mathrm{s}}$, while CMXPEM adsorbed more $\mathrm{Na}^{+}$compared to $\mathrm{Mg}^{2+}, \mathrm{CMX}$ and CIMS showed the opposite trend during adsorption steps (Figure $4 \mathrm{~A}-\mathrm{C})$. The affinities of the membranes toward either $\mathrm{Na}^{+}$or $\mathrm{Mg}^{2+}$ were also confirmed with the effluent concentration data during desorption (Figure 4D-F). To conclude this section, Figure 4 shows that it is possible to switch CMX's selectivity from $\mathrm{Mg}^{2+}$ to $\mathrm{Na}^{+}$by simply coating it with a PEM. Before starting the electrosorption cycles, the ion solution of $4 \mathrm{mM}$ (for each cation) was recirculated through the MCDI cell. Upon this recirculation, the ion concentration was found to slightly increase. However, this deviation has no influence on the final selectivity as we used these increased concentrations to calculate the selectivities.

Next, to facilitate a quantitative comparison, the $\rho_{\mathrm{Mg}}^{\mathrm{Na}}$ values for each type of membrane were calculated based on eq 1 . CMX-PEM showed $\rho_{\mathrm{Mg}}^{\mathrm{Na}}=2.8 \pm 0.2$, whereas $\mathrm{CMX}(0.5 \pm 0.0)$ and CIMS $(0.2 \pm 0.1)$ showed more affinity toward $\mathrm{Mg}^{2+}$ (Figure 5).

Now, we report that PEMs can increase the monovalent ion selectivity in MCDI as well. The affinity of a bare CMX membrane toward divalent cations was also reported by other studies. ${ }^{21,70,71}$ The CMX membrane has a preference for divalent cations, which can be understood by the Coulombic interactions between the negative outermost layer of the membrane and the cations. Since the charge density of $\mathrm{Mg}^{2+}$ is around 6 times higher than that of $\mathrm{Na}^{+56}$ there is a stronger ionic interaction between the bare CMX membrane and $\mathrm{Mg}^{2+}$. On the other hand, the deposition of the PEM on top of the CMX membrane resulted in a rejection of divalent cations, 


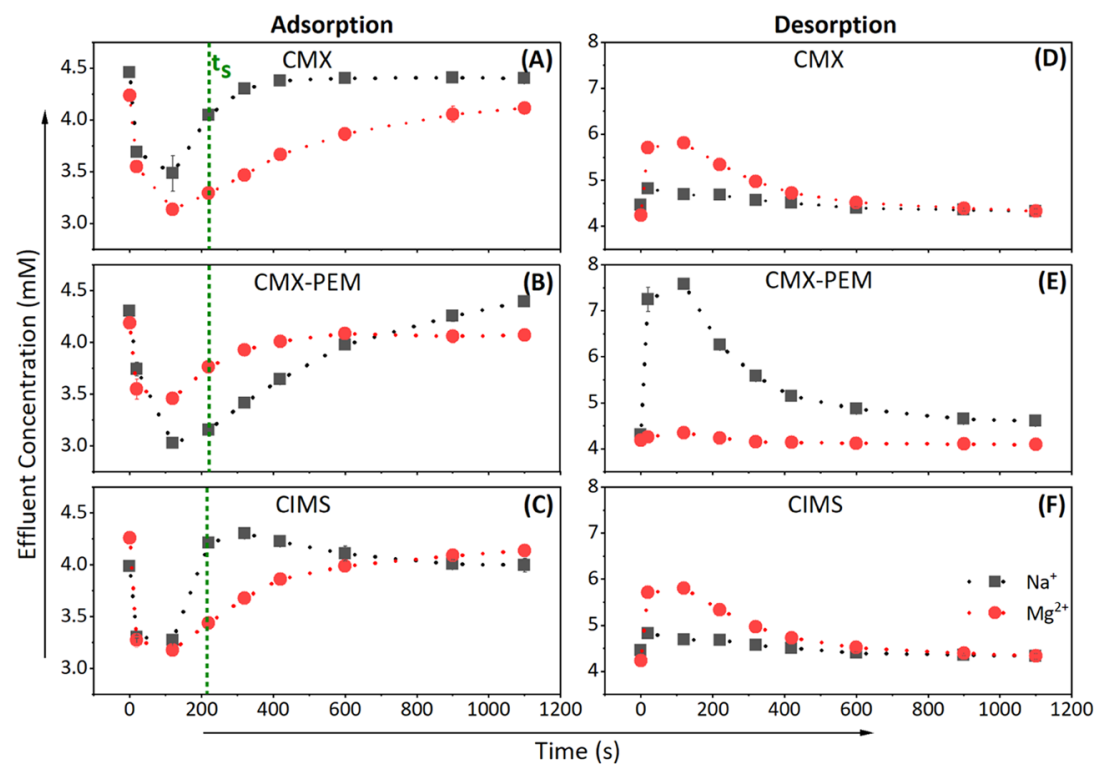

Figure 4. Change in effluent concentrations in time for (A, B, C) adsorption and (D, E, F) desorption steps for CMX, CMX-PEM, and CIMS, respectively. $t_{s}$ indicates the points where the maximum selectivity values were observed during adsorption steps.

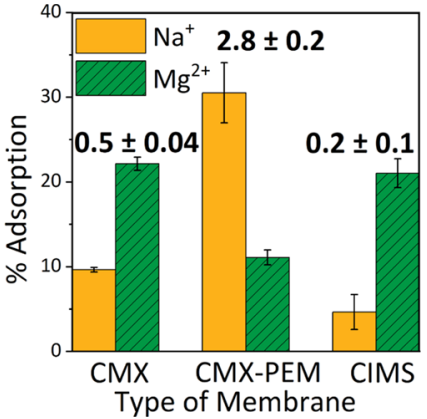

Figure 5. Adsorption percentage and selectivity values of the membranes. Each $\rho_{\mathrm{Mg}}^{\mathrm{Na}}$ was calculated at $t_{\mathrm{s}}$ using the data from three separate experiments including three adsorption steps per experiment.

which can also be rationalized by charge effects. First, the outer layer of the PEM, which is positive in charge, rejects divalent cations more than monovalent cations due to Donnan exclusion. $^{57}$

Second, also the overall high charge density of PEM coatings may contribute to this effect. It is known that the PAH/PSS system shows an over-charge compensation effect. ${ }^{72,73}$ In a recent reflectometry study by Rijnaarts et al., ${ }^{54}$ this effect was found for the PAH/PSS system after four bilayers onward and the excess of positive charge further increased for thicker multilayers. In our study, we used similar coating conditions and hence it is reasonable to assume that our (PAH/PSS) 5.5 system has an overall positive charge.

To test the PEM stability during the 40-cycle MCDI operation of the CMX-PEM membrane, ICP-OES samples were taken from the 5 th, 25 th, and 40 th cycle. The average $\rho_{\mathrm{Mg}}^{\mathrm{Na}}$ value was found to be $2.5 \pm 0.1$, meaning that the PEM was stable during the 40-cycle experiment. The selectivity values per each cycle are provided in the Supporting Information, Table S2.

To facilitate a comparison, an overview of different approaches that achieved mono- or divalent cation selectivity in CDI was made (Table 1). From this table, it becomes clear that different experimental conditions and/or modification of electrodes or membranes can change selectivity values. In more detail, it shows that the selectivity does not only depend on the chemical structure or the surface modification of the membrane, but also on many other factors, such as the pore size and surface area of the carbon electrode, ${ }^{74,75}$ ionic charge, the hydrated size of cations, ${ }^{41}$ the composition and initial concentration of the feed solution, ${ }^{21,41}$ and operational

Table 1. Overview of Selectivity Values for Various Reported CDI Systems/Conditions Toward Either Mono- or Divalent Cations in CDI. Cited Work With Values For $\rho$ Made Use of Equation 1

selective layer/optimization
operational conditions
operational conditions
operational conditions
operational conditions
Ca-alginate layer
nanocomposite layer
CMX membrane
CMX-PEM
CIMS

feed ratio $\left(\mathrm{Na} / \mathrm{X}^{2+}\right)$
5
1
25
1.3
1
$10-1$
1
1
1

\begin{tabular}{ll}
\multicolumn{1}{c}{ selectivity value } & reference \\
$\mathrm{Na}^{+}>\mathrm{Ca}^{2+}=5 \mathrm{Ca}^{2+}>\mathrm{Na}^{+}=3$ & 39 \\
1.5 & 41 \\
6 & 20 \\
$2.8-3.3$ & 21 \\
2.5 & 40 \\
$\mathrm{Ca}^{2+}>\mathrm{Na}^{+}=3.5-5.4$ & 37 \\
0.5 & this work \\
2.8 & this work \\
0.2 & this work
\end{tabular}
(a)

$a$
$\rho_{\mathrm{Na}}^{\mathrm{Ca}}$
$\rho_{\mathrm{Na}}^{\mathrm{Ca}}$
$\rho_{\mathrm{Na}}^{\mathrm{Ca}}$
$\rho_{\mathrm{Na}}^{\mathrm{Ca} b}$
$\mathrm{~S}_{\mathrm{t} / \mathrm{c}}{ }^{\mathrm{Ca}}$
$\rho_{\mathrm{Mg}}^{\mathrm{Na}}$
$\rho_{\mathrm{Mg}}^{\mathrm{Ma}}$
$\rho_{\mathrm{Mg}}^{\mathrm{Na}}$
reference

${ }^{a}$ Based on Gouy-Chapman theoretical approach. ${ }^{b}$ See reference for the selectivity definition. ${ }^{c}$ Calculated based on eq 1. 
parameters (applied voltage, ${ }^{41}$ current density, ${ }^{21}$ operating time, ${ }^{38}$ and flow rate ${ }^{38,76}$ ).

To understand the effect of the addition of a PEM on monovalent cation selectivity, all of the operational conditions (i.e., flow rate, current, time) were kept constant for each type of membrane. While it is difficult to compare selectivities obtained from different desalination techniques, and higher selectivities have been reported for the combination of LbL and electrodialysis, ${ }^{49,67}$ our results are in line with the findings of other electrodialysis studies that also employed LbL-coated Neosepta ion-exchange membranes. ${ }^{52,54,66}$ For example, Abdu et al. deposited polyethylenimine/PSS films on a Neosepta CMX ion-exchange membrane and obtained a $\mathrm{Na}^{+} / \mathrm{Ca}^{2+}$ selectivity of $1.4 .^{52}$ Similarly, Mulyati et al. found that Neosepta anion-exchange membranes modified with $\mathrm{PAH} /$ PSS layers exhibit $\mathrm{Cl}^{-} / \mathrm{SO}_{4}{ }^{2-}$ selectivities of $\sim 2.5 .^{66} \mathrm{CMX}$ PEM has a promising $\mathrm{Na}^{+}$selectivity compared to the other CDI systems listed in Table 1, although it has to be acknowledged that the selectivity is time-dependent during electrosorption. To optimize the process and improve the separation at $t_{\mathrm{s}}$, a potential of $0 \mathrm{~V}$ can be applied to the system, followed by a washing step of the electrode to obtain a $\mathrm{Na}^{+}$rich solution after each cycle. Once the desired amount of $\mathrm{Na}^{+}$ has been removed, the $\mathrm{Mg}^{2+}$ that is still present in the treated solution can be removed with a posttreatment step.

Calculations of Energy Consumption. Capacitive deionization is a well-known technology used for water desalination with low-energy consumption. Therefore, the paramount parameters that should be taken into account when evaluating the CDI performance for ion selectivity using modified membranes are salt adsorption capacity (SAC, in $\mathrm{mg} / \mathrm{g}$ ), the charge efficiency $(\Lambda)$, and specific energy consumption $(\eta)$. SAC is the amount of salt removed during electrosorption, and it was calculated by integrating salt concentration over time using eq $4 . \Lambda$ indicates how much of the charge provided to the electrode is effectively used for electrosorption. In this sense, the closer the value of $\Lambda$ to $100 \%$, the better. In practice, $100 \%$ charge efficiency is seldom achieved due to electrode degradation, co-ion repulsion, cell resistivity, and Faradaic reactions that usually take place together with the electrode polarization.

Table 2 summarizes the obtained SAC, $\Lambda$, and $\eta$ values of CDI experiments carried out with CMX-PEM, CMX, and CIMS membranes.

Table 2. Comparison of Salt Adsorption Capacity, Charge Efficiency, and Specific Energy Consumption of the Membranes

\begin{tabular}{lclc} 
type of membrane & SAC $(\mathrm{mg} / \mathrm{g})$ & $\Lambda(\%)$ & $\eta(\mathrm{kJ} / \mathrm{g})$ \\
CMX-PEM & $3.5 \pm 0.6$ & $68 \pm 14$ & $2.7 \pm 0.6$ \\
CMX & $3.5 \pm 0.3$ & $69 \pm 9$ & $2.8 \pm 0.4$ \\
CIMS & $2.5 \pm 0.3$ & $54 \pm 7$ & $3.8 \pm 0.5$ \\
\hline
\end{tabular}

It is noted that water splitting near the polyelectrolyte/ membrane interface may reduce the current efficiency and form insoluble metal hydroxides to foul the membrane. ${ }^{49}$ However, we did not observe this issue in our system. The SAC value for CMX and PEM-CMX did not differ from each other, indicating that there is no significant effect of PEM on the SAC (Table 2). Also, the constant SAC value of PEMCMX during the long-term desalination process (SI, Table S1) is a strong indication of the stability of the PEM. The $\Lambda$ values for CMX and CMX-PEM membranes were around 69\%, showing that the addition of PEM has no significant effect on $\Lambda$. These values are slightly lower than those for CMX reported in the literature $(88 \pm 5 \%),{ }^{77}$ which can be associated with the type of the carbon electrode and the cell design. Furthermore, since we did not have a single-salt solution, ICPOES data were used to calculate the amounts of salt removed. However, due to the limited availability of concentration data points, this approach may have resulted in an underestimation of the integrated values of salt removal, lowering $\Delta n$, and hence the $\Lambda$ values. Furthermore, any leakage current would reduce the effective applied current and hence decrease the $\Lambda$ values. The $\Lambda$ value of the CIMS membrane was even lower (54\%). The results show that the modified and bare CMX membranes have a better performance than the CIMS membrane, which can be rationalized by a higher resistance due to the cross-linking nature of the CIMS membrane. ${ }^{54}$

Following the same trend, $\eta$ of the CIMS membrane was higher than $\eta$ of the CMX membrane. This was expected since $\eta$ is linked to $\Lambda$, according to eqs 2 and 3 . The $\eta$ values observed during the electrosorption process were comparable with the literature values. ${ }^{77,78}$

\section{CONCLUSIONS}

This study distinctively describes the control of monovalent/ divalent ion selectivity in the process of membrane capacitive deionization (MCDI) simply by adding a thin polyelectrolyte multilayer (PEM) onto the membrane surface. PEMs have already been used as ion-selective coatings, mainly in pressuredriven, and more recently also in electro-driven processes, in particular electrodialysis. Based on the promising results of PEMs in other desalination processes, we combined, for the first time, PEMs and MCDI to obtain monovalent cation selectivity. A thorough interface analysis, investigation of the layer stability, and a detailed comparison with selectivity performance of various reported CDI systems/conditions are included in our study. For the resulting CMX-PEM membrane, we obtained a $\mathrm{Na}^{+} / \mathrm{Mg}^{2+}$ selectivity of almost three, while the bare CMX showed a preference for $\mathrm{Mg}^{2+}$. These results provide a proof-of-concept for a smooth switching from a $\mathrm{Mg}^{2+}$-selective membrane to a $\mathrm{Na}^{+}$-selective membrane by straightforward modification with a PEM. Furthermore, it is shown that the layers have high stability even after long-term desalination operation. Our work demonstrates a new way of achieving ion selectivity in CDI using PEMs. Given the large toolbox of available polyelectrolytes and variety of polyelectrolyte functionalization schemes, we anticipate that our modular approach may facilitate the further development of the separation and recovery of other ions by controlling interfacial properties at a nanoscale.

\section{ASSOCIATED CONTENT}

\section{SI Supporting Information}

The Supporting Information is available free of charge at https://pubs.acs.org/doi/10.1021/acsami.0c05664.

Schematic representation of the MCDI system, the abundance of elements per layer, XPS wide-scan spectra of the LbL-coated gold substrates, ellipsometer and AFM data, conductivity and current change in time during the long-term desalination process, the table of Coulombic efficiency, desalination capacity, and salt 
adsorption capacity values, and the table of the selectivity values for each type of membrane (PDF)

\section{AUTHOR INFORMATION}

\section{Corresponding Authors}

Rafael L. Zornitta - Laboratory of Organic Chemistry, Wageningen University, 6708 WE Wageningen, The Netherlands; Phone: +31-317484810;

Email: rafael.linzmeyerzornitta@wur.nl

Louis C.P.M. de Smet - Laboratory of Organic Chemistry, Wageningen University, 6708 WE Wageningen, The Netherlands; (1) orcid.org/0000-0001-7252-4047; Phone: +31-317481268; Email: louis.desmet@wur.nl

\section{Authors}

Sevil Sahin - Laboratory of Organic Chemistry, Wageningen University, 6708 WE Wageningen, The Netherlands; () orcid.org/0000-0001-7581-2466

Jouke E. Dykstra - Environmental Technology, Wageningen University, 6708 WG Wageningen, The Netherlands; (1) orcid.org/0000-0002-0377-4779

Han Zuilhof - Laboratory of Organic Chemistry, Wageningen University, 6708 WE Wageningen, The Netherlands; School of Pharmaceutical Science and Technology, Tianjin University, Tianjin 300072, China; Department of Chemical and Materials Engineering, Faculty of Engineering, King Abdulaziz University, Jeddah 21589, Saudi Arabia; (1) orcid.org/00000001-5773-8506

Complete contact information is available at: https://pubs.acs.org/10.1021/acsami.0c05664

\section{Author Contributions}

L.C.P.M.d.S. and S.S. devised the project. S.S. planned and performed the experiments. S.S., L.C.P.M.d.S., R.L.Z., J.E.D., and H.Z. analyzed the data. L.C.P.M.d.S. guided the project. S.S. wrote the first draft of the paper, and all authors gave input.

\section{Funding}

This study was supported by the European Research Council (ERC Consolidator Grant 682444, E-motion, PI De Smet).

\section{Notes}

The authors declare no competing financial interest.

\section{ACKNOWLEDGMENTS}

The authors thank Wetsus-European centre of excellence for sustainable water technology (Leeuwarden, the Netherlands) for the design of the CDI cell, Barend van Lagen and Dr. Sidharam P. Pujari for AFM and XPS measurements and providing insight and expertize about surface characterization, M.Sc. Lucas Teunissen for ellipsometer measurements, and Voltea BV, Netherlands, for the porous carbon electrode deposited on the graphite foil. S.S. thanks Dr. Pina Fritz, M.Sc. Kaustub Singh, M.Sc. Jayaruwan Gamaethiralalage (Wageningen University), and M.Sc. Tania Mubita Zambrano (Wetsus) for fruitful discussions regarding CDI experiments.

\section{REFERENCES}

(1) Zhang, X.; Zuo, K.; Zhang, X.; Zhang, C.; Liang, P. Selective Ion Separation by Capacitive Deionization (CDI) Based Technologies: A State-of-the-Art Review. Environ. Sci. Water Res. Technol. 2020, 6, $243-257$.
(2) Volfkovich, Y. M. Capacitive Deionization of Water (A Review). Russ. J. Electrochem. 2020, 56, 18-51.

(3) Choi, J.; Dorji, P.; Shon, H. K.; Hong, S. Applications of Capacitive Deionization: Desalination, Softening, Selective Removal, and Energy Efficiency. Desalination 2019, 449, 118-130.

(4) Zhu, E.; Hong, X.; Ye, Z.; Hui, K. S.; Hui, K. N. Influence of Various Experimental Parameters on the Capacitive Removal of Phosphate from Aqueous Solutions Using LDHs/AC Composite Electrodes. Sep. Purif. Technol. 2019, 215, 454-462.

(5) Bian, Y.; Chen, X.; Lu, L.; Liang, P.; Ren, Z. J. Concurrent Nitrogen and Phosphorus Recovery Using Flow-Electrode Capacitive Deionization. ACS Sustainable Chem. Eng. 2019, 7, 7844-7850.

(6) Jiang, J.; Kim, D. I.; Dorji, P.; Phuntsho, S.; Hong, S.; Shon, H. K. Phosphorus Removal Mechanisms from Domestic Wastewater by Membrane Capacitive Deionization and System Optimization for Enhanced Phosphate Removal. Process Saf. Environ. Prot. 2019, 126, 44-52.

(7) Kim, Y. J.; Choi, J. H. Selective Removal of Nitrate Ion Using a Novel Composite Carbon Electrode in Capacitive Deionization. Water Res. 2012, 46, 6033-6039.

(8) Gan, L.; Wu, Y.; Song, H.; Zhang, S.; Lu, C.; Yang, S.; Wang, Z.; Jiang, B.; Wang, C.; Li, A. Selective Removal of Nitrate Ion Using a Novel Activated Carbon Composite Carbon Electrode in Capacitive Deionization. Sep. Purif. Technol. 2019, 212, 728-736.

(9) Hawks, S. A.; Cerón, M. R.; Oyarzun, D. I.; Pham, T. A.; Zhan, C.; Loeb, C. K.; Mew, D.; Deinhart, A.; Wood, B. C.; Santiago, J. G.; et al. Using Ultramicroporous Carbon for the Selective Removal of Nitrate with Capacitive Deionization. Environ. Sci. Technol. 2019, 53, 10863-10870.

(10) Mubita, T. M.; Dykstra, J. E.; Biesheuvel, P. M.; van der Wal, A.; Porada, S. Selective Adsorption of Nitrate over Chloride in Microporous Carbons. Water Res. 2019, 164, No. 114885.

(11) Shi, W.; Liu, X.; Ye, C.; Cao, X.; Gao, C.; Shen, J. Efficient Lithium Extraction by Membrane Capacitive Deionization Incorporated with Monovalent Selective Cation Exchange Membrane. Sep. Purif. Technol. 2019, 210, 885-890.

(12) Kim, S.; Yoon, H.; Shin, D.; Lee, J.; Yoon, J. Electrochemical Selective Ion Separation in Capacitive Deionization with Sodium Manganese Oxide. J. Colloid Interface Sci. 2017, 506, 644-648.

(13) Zhang, C.; Ma, J.; Waite, T. D. Ammonia-Rich Solution Production from Wastewaters Using Chemical-Free Flow-Electrode Capacitive Deionization. ACS Sustainable Chem. Eng. 2019, 7, 64806485.

(14) Pan, J.; Zheng, Y.; Ding, J.; Gao, C.; Van Der Bruggen, B.; Shen, J. Fluoride Removal from Water by Membrane Capacitive Deionization with a Monovalent Anion Selective Membrane. Ind. Eng. Chem. Res. 2018, 57, 7048-7053.

(15) Liu, P.; Yan, T.; Zhang, J.; Shi, L.; Zhang, D. Separation and Recovery of Heavy Metal Ions and Salt Ions from Wastewater by 3D Graphene-Based Asymmetric Electrodes: via Capacitive Deionization. J. Mater. Chem. A 2017, 5, 14748-14757.

(16) Ji, Q.; An, X.; Liu, H.; Guo, L.; Qu, J. Electric Double-Layer Effects Induce Separation of Aqueous Metal Ions. ACS Nano 2015, 9, $10922-10930$.

(17) Huang, Z.; Lu, L.; Cai, Z.; Ren, Z. J. Individual and Competitive Removal of Heavy Metals Using Capacitive Deionization. J. Hazard. Mater. 2016, 302, 323-331.

(18) Chen, R.; Sheehan, T.; Ng, J. L.; Brucks, M.; Su, X. Capacitive Deionization and Electrosorption for Heavy Metal Removal. Environ. Sci. Water Res. Technol. 2020, 6, 258-282.

(19) Choi, J.; Lee, H.; Hong, S. Capacitive Deionization (CDI) Integrated with Monovalent Cation Selective Membrane for Producing Divalent Cation-Rich Solution. Desalination 2016, 400, $38-46$.

(20) He, C.; Ma, J.; Zhang, C.; Song, J.; Waite, T. D. Short-Circuited Closed-Cycle Operation of Flow-Electrode CDI for Brackish Water Softening. Environ. Sci. Technol. 2018, 52, 9350-9360. 
(21) Wang, L.; Lin, S. Mechanism of Selective Ion Removal in Membrane Capacitive Deionization for Water Softening. Environ. Sci. Technol. 2019, 53, 5797-5804.

(22) Savvas, D.; Mantzos, N.; Barouchas, P. E.; Tsirogiannis, I. L.; Olympios, C.; Passam, H. C. Modelling Salt Accumulation by a Bean Crop Grown in a Closed Hydroponic System in Relation to Water Uptake. Sci. Hortic. 2007, 111, 311-318.

(23) Savvas, D.; Chatzieustratiou, E.; Pervolaraki, G.; Gizas, G.; Sigrimis, N. Modelling $\mathrm{Na}$ and $\mathrm{Cl}$ Concentrations in the Recycling Nutrient Solution of a Closed-Cycle Pepper Cultivation. Biosyst. Eng. 2008, 99, 282-291.

(24) Singh, K.; Qian, Z.; Biesheuvel, P. M.; Zuilhof, H.; Porada, S.; de Smet, L. C. P. M. Nickel Hexacyanoferrate Electrodes for High Mono/Divalent Ion-Selectivity in Capacitive Deionization. Desalination 2020, 481, No. 114346.

(25) Qian, Z.; Miedema, H.; de Smet, L. C. P. M.; Sudhölter, E. J. R. Modelling the Selective Removal of Sodium Ions from Greenhouse Irrigation Water Using Membrane Technology. Chem. Eng. Res. Des. 2018, 134, 154-161.

(26) Zhang, J. L.; Flowers, T. J.; Wang, S. M. Mechanisms of Sodium Uptake by Roots of Higher Plants. Plant Soil 2010, 326, 45-60.

(27) Suss, M. E.; Porada, S.; Sun, X.; Biesheuvel, P. M.; Yoon, J.; Presser, V. Water Desalination via Capacitive Deionization: What Is It and What Can We Expect from It? Energy Environ. Sci. 2015, 8, 2296-2319.

(28) Kim, J. S.; Kim, C. S.; Shin, H. S.; Rhim, J. W. Application of Synthesized Anion and Cation Exchange Polymers to Membrane Capacitive Deionization (MCDI). Macromol. Res. 2015, 23, 360-366. (29) Qin, M.; Deshmukh, A.; Epsztein, R.; Patel, S. K.; Owoseni, O. M.; Walker, W. S.; Elimelech, M. Comparison of Energy Consumption in Desalination by Capacitive Deionization and Reverse Osmosis. Desalination 2019, 455, 100-114.

(30) Ramachandran, A.; Oyarzun, D. I.; Hawks, S. A.; Campbell, P. G.; Stadermann, M.; Santiago, J. G. Comments on "Comparison of Energy Consumption in Desalination by Capacitive Deionization and Reverse Osmosis.". Desalination 2019, 461, 30-36.

(31) Qin, M.; Deshmukh, A.; Epsztein, R.; Patel, S. K.; Owoseni, O. M.; Walker, W. S.; Elimelech, M. Response to Comments on "Comparison of Energy Consumption in Desalination by Capacitive Deionization and Reverse Osmosis.". Desalination 2019, 462, 48-55.

(32) Lin, S. Energy Efficiency of Desalination: Fundamental Insights from Intuitive Interpretation. Environ. Sci. Technol. 2020, 54, 76-84.

(33) Porada, S.; Zhang, L.; Dykstra, J. E. Energy Consumption in Membrane Capacitive Deionization and Comparison with Reverse Osmosis. Desalination 2020, 455, 100-114.

(34) Hassanvand, A.; Wei, K.; Talebi, S.; Chen, G. Q.; Kentish, S. E. The Role of Ion Exchange Membranes in Membrane Capacitive Deionisation. Membranes. 2017, 7, 1-23.

(35) Li, H.; Zou, L. Ion-Exchange Membrane Capacitive Deionization: A New Strategy for Brackish Water Desalination. Desalination 2011, 275, 62-66.

(36) Porada, S.; Zhao, R.; Van Der Wal, A.; Presser, V.; Biesheuvel, P. M. Review on the Science and Technology of Water Desalination by Capacitive Deionization. Prog. Mater. Sci. 2013, 58, 1388-1442.

(37) Kim, J.; Jain, A.; Zuo, K.; Verduzco, R.; Walker, S.; Elimelech, M.; Zhang, Z.; Zhang, X.; Li, Q. Removal of Calcium Ions from Water by Selective Electrosorption Using Target-Ion Specific Nanocomposite Electrode. Water Res. 2019, 160, 445-453.

(38) Seo, S. J.; Jeon, H.; Lee, J. K.; Kim, G. Y.; Park, D.; Nojima, H.; Lee, J.; Moon, S. H. Investigation on Removal of Hardness Ions by Capacitive Deionization (CDI) for Water Softening Applications. Water Res. 2010, 44, 2267-2275.

(39) Zhao, R.; van Soestbergen, M.; Rijnaarts, H. H. M.; van der Wal, A.; Bazant, M. Z.; Biesheuvel, P. M. Time-Dependent Ion Selectivity in Capacitive Charging of Porous Electrodes. J. Colloid Interface Sci. 2012, 384, 38-44.

(40) Yoon, H.; Lee, J.; Kim, S. R.; Kang, J.; Kim, S.; Kim, C.; Yoon, J. Capacitive Deionization with Ca-Alginate Coated-Carbon Electrode for Hardness Control. Desalination 2016, 392, 46-53.
(41) Hou, C. H.; Huang, C. Y. A Comparative Study of Electrosorption Selectivity of Ions by Activated Carbon Electrodes in Capacitive Deionization. Desalination 2013, 314, 124-129.

(42) Decher, G.; Hong, J.-D.; Schmitt, J. Buildup of Ultrathin Multilayer Films by a Self-assembly Process, III. Consecutively Alternating Adsorption of Anionic and Cationic Polyelectrolytes on Charged Surfaces. Thin Solid Films 1992, 210-211, 831-835.

(43) Decher, G. Fuzzy Nanoassemblies: Toward Layered Polymeric Multicomposites. Science 1997, 277, 1232-1237.

(44) Richardson, J. J.; Cui, J.; Björnmalm, M.; Braunger, J. A.; Ejima, H.; Caruso, F. Innovation in Layer-by-Layer Assembly. Chem. Rev. 2016, 116, 14828-14867.

(45) Cao, Z.; Gordiichuk, P. I.; Loos, K.; Sudhölter, E. J. R.; de Smet, L. C. P. M. The Effect of Guanidinium Functionalization on the Structural Properties and Anion Affinity of Polyelectrolyte Multilayers. Soft Matter 2016, 12, 1496-1505.

(46) Paltrinieri, L.; Wang, M.; Sachdeva, S.; Besseling, N. A. M.; Sudhölter, E. J. R.; de Smet, L. C. P. M. Fe3O4 Nanoparticles Coated with a Guanidinium-Functionalized Polyelectrolyte Extend the $\mathrm{pH}$ Range for Phosphate Binding. J. Mater. Chem. A 2017, 5, 1847618485 .

(47) Paltrinieri, L.; Remmen, K.; Müller, B.; Chu, L.; Köser, J.; Wintgens, T.; Wessling, M.; de Smet, L. C. P. M.; Sudhölter, E. J. R. Improved Phosphoric Acid Recovery from Sewage Sludge Ash Using Layer-by-Layer Modified Membranes. J. Membr. Sci. 2019, 587, No. 117162.

(48) Cheng, C.; Yaroshchuk, A.; Bruening, M. L. Fundamentals of Selective Ion Transport through Multilayer Polyelectrolyte Membranes. Langmuir 2013, 29, 1885-1892.

(49) White, N.; Misovich, M.; Alemayehu, E.; Yaroshchuk, A.; Bruening, M. L. Highly Selective Separations of Multivalent and Monovalent Cations in Electrodialysis through Nafion Membranes Coated with Polyelectrolyte Multilayers. Polymer 2016, 103, 478485.

(50) Krasemann, L.; Tieke, B. Selective Ion Transport across SelfAssembled Alternating Multilayers of Cationic and Anionic Polyelectrolytes. Langmuir 2000, 16, 287-290.

(51) Cheng, W.; Liu, C.; Tong, T.; Epsztein, R.; Sun, M.; Verduzco, R.; Ma, J.; Elimelech, M. Selective Removal of Divalent Cations by Polyelectrolyte Multilayer Nanofiltration Membrane: Role of Polyelectrolyte Charge, Ion Size, and Ionic Strength. J. Membr. Sci. 2018, 559, 98-106.

(52) Abdu, S.; Martí-Calatayud, M. C.; Wong, J. E.; GarcíaGabaldo'n, M.; Wessling, M. Layer-by-Layer Modification of Cation Exchange Membranes Controls Ion Selectivity and Water Splitting. ACS Appl. Mater. Interfaces 2014, 6, 1843-1854.

(53) Cheng, C.; White, N.; Shi, H.; Robson, M.; Bruening, M. L. Cation Separations in Electrodialysis through Membranes Coated with Polyelectrolyte Multilayers. Polymer 2014, 55, 1397-1403.

(54) Rijnaarts, T.; Reurink, D. M.; Radmanesh, F.; de Vos, W. M.; Nijmeijer, K. Layer-by-Layer Coatings on Ion Exchange Membranes: Effect of Multilayer Charge and Hydration on Monovalent Ion Selectivities. J. Membr. Sci. 2019, 570-571, 513-521.

(55) Stanton, B. W.; Harris, J. J.; Miller, M. D.; Bruening, M. L. Ultrathin, Multilayered Polyelectrolyte Films as Nanofiltration Membranes. Langmuir 2003, 19, 7038-7042.

(56) Tansel, B. Significance of Thermodynamic and Physical Characteristics on Permeation of Ions during Membrane Separation: Hydrated Radius, Hydration Free Energy and Viscous Effects. Sep. Purif. Technol. 2012, 86, 119-126.

(57) Ouyang, L.; Malaisamy, R.; Bruening, M. L. Multilayer Polyelectrolyte Films as Nanofiltration Membranes for Separating Monovalent and Divalent Cations. J. Membr. Sci. 2008, 310, 76-84.

(58) Zhu, Y.; Ahmad, M.; Yang, L.; Misovich, M.; Yaroshchuk, A.; Bruening, M. L. Adsorption of Polyelectrolyte Multilayers Imparts High Monovalent/Divalent Cation Selectivity to Aliphatic Polyamide Cation-Exchange Membranes. J. Membr. Sci. 2017, 537, 177-185.

(59) de Grooth, J.; Oborný, R.; Potreck, J.; Nijmeijer, K.; de Vos, W. M. The Role of Ionic Strength and Odd-Even Effects on the 
Properties of Polyelectrolyte Multilayer Nanofiltration Membranes. J. Membr. Sci. 2015, 475, 311-319.

(60) Kuzmyn, A. R.; De Los Santos Pereira, A.; Pop-Georgievski, O.; Bruns, M.; Brynda, E.; Rodriguez-Emmenegger, C. Exploiting End Group Functionalization for the Design of Antifouling Bioactive Brushes. Polym. Chem. 2014, 5, 4124-4131.

(61) Hinterwirth, H.; Kappel, S.; Waitz, T.; Prohaska, T.; Lindner, W.; Lämmerhofer, M. Quantifying Thiol Ligand Density of SelfAssembled Monolayers on Gold Nanoparticles by Inductively Coupled Plasma-Mass Spectrometry. ACS Nano 2013, 7, 1129-1136.

(62) Lee, J.; Srimuk, P.; Zwingelstein, R.; Zornitta, R. L.; Choi, J.; Kim, C.; Presser, V. Sodium Ion Removal by Hydrated Vanadyl Phosphate for Electrochemical Water Desalination. J. Mater. Chem. A 2019, 7, 4175-4184.

(63) Suss, M. E. Size-based ion selectivity of micropore electric double layers in capacitive deionization electrodes. J. Electrochem. Soc. 2017, 164, E270-E275.

(64) Kolasińska, M.; Warszyński, P. The Effect of Support Material and Conditioning on Wettability of PAH/PSS Multilayer Films. Bioelectrochemistry 2005, 66, 65-70.

(65) Gentile, P.; Frongia, M. E.; Cardellach, M.; Miller, C. A.; Stafford, G. P.; Leggett, G. J.; Hatton, P. V. Functionalised Nanoscale Coatings Using Layer-by-Layer Assembly for Imparting Antibacterial Properties to Polylactide-Co-Glycolide Surfaces. Acta Biomater. 2015, $21,35-43$.

(66) Mulyati, S.; Takagi, R.; Fujii, A.; Ohmukai, Y.; Matsuyama, H. Simultaneous Improvement of the Monovalent Anion Selectivity and Antifouling Properties of an Anion Exchange Membrane in an Electrodialysis Process, Using Polyelectrolyte Multilayer Deposition. J. Membr. Sci. 2013, 431, 113-120.

(67) White, N.; Misovich, M.; Yaroshchuk, A.; Bruening, M. L. Coating of Nafion Membranes with Polyelectrolyte Multilayers to Achieve High Monovalent/Divalent Cation Electrodialysis Selectivities. ACS Appl. Mater. Interfaces 2015, 7, 6620-6628.

(68) Li, L.; Wu, L.; Wu, F.; Song, S.; Zhang, X.; Fu, C.; Yuan, D.; Xiang, Y. Review - Recent Research Progress in Surface Modification of $\mathrm{LiFePO}_{4}$ Cathode Materials. J. Electrochem. Soc. 2017, 164, A2138-A2150.

(69) Dykstra, J. E.; Dijkstra, J.; Van der Wal, A.; Hamelers, H. V. M.; Porada, S. On-Line Method to Study Dynamics of Ion Adsorption from Mixtures of Salts in Capacitive Deionization. Desalination 2016, $390,47-52$.

(70) Sata, T.; Sata, T.; Yang, W. Studies on Cation-Exchange Membranes Having Permselectivity between Cations in Electrodialysis. J. Membr. Sci. 2002, 206, 31-60.

(71) Luo, T.; Abdu, S.; Wessling, M. Selectivity of Ion Exchange Membranes: A Review. J. Membr. Sci. 2018, 555, 429-454.

(72) Riegler, H.; Essler, F. Polyelectrolytes. 2: Intrinsic or Extrinsic Charge Compensation? Quantitative Charge Analysis of PAH/PSS Multilayers. Langmuir 2002, 18, 6694-6698.

(73) Joseph, N.; Ahmadiannamini, P.; Hoogenboom, R.; Vankelecom, I. F. J. Layer-by-Layer Preparation of Polyelectrolyte Multilayer Membranes for Separation. Polym. Chem. 2014, 5, 18171831.

(74) Gabelich, C. J.; Tran, T. D.; Suffet, I. H. Electrosorption of Inorganic Salts from Aqueous Solution Using Carbon Aerogels. Environ. Sci. Technol. 2002, 36, 3010-3019.

(75) Avraham, E.; Yaniv, B.; Soffer, A.; Aurbach, D. Developing Ion Electroadsorption Stereoselectivity, by Pore Size Adjustment with Chemical Vapor Deposition onto Active Carbon Fiber Electrodes. Case of $\mathrm{Ca}^{2+} / \mathrm{Na}^{+}$Separation in Water Capacitive Desalination. J. Phys. Chem. C 2008, 112, 7385-7389.

(76) Mossad, M.; Zhang, W.; Zou, L. Using Capacitive Deionisation for Inland Brackish Groundwater Desalination in a Remote Location. Desalination 2013, 308, 154-160.

(77) Yoon, H.; Jo, K.; Kim, K. J.; Yoon, J. Effects of Characteristics of Cation Exchange Membrane on Desalination Performance of Membrane Capacitive Deionization. Desalination 2019, 458, 116121.
(78) Zornitta, R. L.; Srimuk, P.; Lee, J.; Krüner, B.; Aslan, M.; Ruotolo, L. A. M.; Presser, V. Charge and Potential Balancing for Optimized Capacitive Deionization Using Lignin-Derived, Low-Cost Activated Carbon Electrodes. ChemSusChem 2018, 11, 2101-2113.

\section{NOTE ADDED AFTER ASAP PUBLICATION}

This paper originally published ASAP on July 15, 2020. Due to a production error, the author initials in ref 63 were incorrect. The revised version was reposted on July 15, 2020. 